\title{
PROMOÇÃO À SAÚDE BIOPSICOSSOCIAL DE CRIANÇAS E ADOLESCENTES NO CONTEXTO DA COVID-19: RELATO DE EXPERIÊNCIA
}

\section{THE PROMOTION OF BIOPSYCHOSOCIAL HEALTH OF CHILDREN AND ADOLESCENTS IN SOCIAL ISOLATION IN THE CONTEXT OF COVID-19: AN EXPERIENCE REPORT}

\author{
Rozane Pereira de Sousa* \\ ORCID: https://orcid.org/0000-0002-2619-8161 \\ Amanda Mayara de Sousa Silva** \\ ORCID: https://orcid.org/0000-0002-4311-5882 \\ Ana Júlia Benício da Silva*** \\ ORCID: https://orcid.org/0000-0001-5637-6005 \\ Raniel Eduardo da Silva**** \\ ORCID: https://orcid.org/0000-0002-6923-1865 \\ Ruan Souza Alixandre***** \\ ORCID: https://orcid.org/0000-0003-4009-2176 \\ Yasmim Cristie Santana Pereira****** \\ ORCID: https://orcid.org/0000-0002-7329-4092
}

\section{Resumo}

Este relato de experiência tem por objetivo descrever as vivências de acadêmicos em atividades desenvolvidas no projeto de extensão: "Promoção à Saúde Biopsicossocial de Crianças e Adolescentes em Isolamento Social no Contexto da Covid-19". A proposta contemplou ações à distância e presenciais, respeitando-se o distanciamento social e as medidas de prevenção à disseminação do SARS-COV-2. As ações não presenciais foram difundidas através das redes sociais e destinadas à comunidade de uma Escola de Futebol no sertão paraibano. As temáticas exploradas buscaram auxiliar no enfrentamento da pandemia, além de proporcionar informações com respaldo científico sobre diversos temas pertinentes à infância e adolescência. Dessa forma, o projeto de extensão foi de grande valia, pois proporcionou o acesso de maneira prática e segura às novas atualizações sobre a COVID-19, formas de se proteger individualmente e coletivamente, promoção ao desenvolvimento biopsicossocial, e, além disso, foi essencial para o aprimoramento do processo formativo dos extensionistas.

Palavras-chave: Saúde; Criança; Adolescente; Pandemia.

\section{Abstract}

This experience report aims to describe the experiences of academics in activities developed in the extension project: "The Promotion of Biopsychosocial Health of Children and Adolescents in Social Isolation in the Context of Covid19". It included remote and face-to-face actions, respecting social distance and measures to prevent the spread of SARS-VOC-2. The non-face-to-face actions were disseminated through social networks and aimed at the community of a Football School in the Paraíba interior. The themes sought to assist in facing the pandemic as well as providing information with scientific support on many relevant topics regarding childhood and adolescence. Thus, the extension project was of great value as it provided access to the new updates on COVID-19 in a practical and safe way in order to provide advice on protecting people, individually and collectively, promoting biopsychosocial development. Besides, it was essential for the improvement of the formative process of the extensionists.

Keywords: Health; Child; Adolescent; Pandemic.

Data recebimento: $03 / 02 / 2021$ Data de aceite: $11 / 05 / 2021$
* Professora da Universidade Federal de Campina Grande (UFCG), Cajazeiras - PB, Brasil. E-mail: enfermeirarozane@gmail.com ** Aluna de Graduação da Universidade Federal de Campina Grande (UFCG), Cajazeiras - PB, Brasil. E-mail: amandamayara15@outlook.com *** Aluna de Graduação da Universidade Federal de Campina Grande (UFCG), Cajazeiras - PB, Brasil. E-mail: juliabenicio15@hotmail.com **** Aluno de Graduação da Universidade Federal de Campina Grande (UFCG), Cajazeiras - PB, Brasil. E-mail: ranielgermano@gmail.com ***** Aluno de Graduação da Universidade Federal de Campina Grande (UFCG), Cajazeiras - PB, Brasil. E-mail: ruansouzaalixandre@gmail.com ****** Aluna de Graduação da Universidade Federal de Campina Grande (UFCG), Cajazeiras - PB, Brasil. E-mail: yasmimcristie@gmail.com 


\section{Introdução}

O cenário mundial para o enfretamento da pandemia da COVID-19 utiliza-se do distanciamento social como a maneira mais eficaz para evitar a contaminação pelo SARS-CoV-2 (Coronavírus), até que sejam implantadas as formas farmacológicas de combate. A quarentena foi uma maneira de resguardar as pessoas e o sistema de saúde, tentando-se evitar um colapso (OPAS, 2020).

Nessa perspectiva, durante a difusão internacional do surto da pandemia da COVID19, os países afetados implementaram gradativamente, no espaço intranacional, diferentes estratégias de isolamento social que impactaram no fechamento de unidades escolares (creches, escolas, colégios, faculdades e universidades) e demandaram formas alternativas à continuidade dos processos de ensino-aprendizagem. Assim, o uso remoto das Tecnologias de Informação e Comunicação (TICs) se tornou a forma predominante para alavancar no contexto emergencial estratégias de Ensino a Distância (EAD), quando possível (SENHORAS, 2020).

Entretanto, as medidas protetivas são compreendidas e aceitas de forma melhor por adultos que percebem de forma integral o momento vivido. Já para a faixa etária da infância e adolescência, o contexto proveniente do distanciamento social é difícil de assimilar, pois as mudanças da rotina os privam dos seus momentos de lazer e do contato com os amigos e entes queridos (NATIVIDADE et al., 2020).

Além disso, o desenvolvimento e estímulo recebido na infância são de grande importância para a formação adulta. Quando se está em uma pandemia com alto nível de disseminação de um vírus e a melhor maneira de se prevenir é ficar em casa, os estímulos e formas de desenvolvimento das crianças se restringem a poucas opções. Isso ocorre porque as pessoas que estarão em contato diário são familiares que, em muitos casos, não sabem ou nunca precisaram lidar com tais necessidades das crianças, privando-as de muitas informações que seriam oferecidas pela escola e convívio externo (LINHARES et al., 2020).

Segundo Florêncio Júnior et al. (2020), os efeitos psicológicos causados pela pandemia acontecem de uma forma negativa, podendo causar também consequências físicas em diversas faixas etárias e, principalmente, nas crianças e nos adolescentes. É provável que os jovens permaneçam mais tempo sentados em atividades sedentárias como vídeo games, jogos no celular, acesso às redes sociais e até aulas remotas, acarretando a redução dos níveis de atividade física, sendo necessária a inserção de momentos ativos em casa.

O projeto de extensão é imprescindível na formação acadêmica. O professor, o aluno e a comunidade podem, juntos, construir um conhecimento diante de outro cenário e obter outra visão, que contribui para adquirirem conhecimentos tanto no espaço acadêmico interno como também fora desse espaço. Trata-se de uma experiência única, que proporciona participar da realidade além do âmbito estudantil, o que contribui além da formação acadêmica, para a formação pessoal (GARCIA, 2012).

Assim, visto o contexto que está sendo vivenciado e como forma de auxiliar os pais e seus filhos durante o período, vislumbrou-se o desenvolvimento de um projeto de extensão 
a fim de promover conhecimentos e informações sobre a COVID-19 para pais, crianças e adolescentes matriculados em uma escola de futebol do sertão paraibano. Buscou-se, ainda, apresentar atividades que poderiam ser realizadas em casa, com materiais de fácil acesso, para que a pandemia não afetasse de forma tão drástica a vida desses indivíduos, além de fortalecer os laços e a interação familiar.

Portanto, este relato de experiência tem por objetivo descrever as atividades desenvolvidas pelo projeto de extensão "Promoção à saúde biopsicossocial de crianças e adolescentes em isolamento social no contexto da COVID-19", da Unidade Acadêmica de Enfermagem, do Centro de Formação de Professores, da Universidade Federal de Campina Grande (UAENF/CFP/UFCG). O referido projeto encontra-se vinculado ao Programa de Bolsas de Extensão da Pró-Reitoria de Extensão (PROBEX/PROPEX), da UFCG, através do Edital PROPEX /N. 07/2020.

\section{Metodologia}

Segundo Almeida et al. (2007, p.461), "um relato de experiência propõe tornar visível e compartilhar com outros profissionais e estudantes uma vivência prática". Dessa forma, este relato descreve as vivências de um grupo de estudantes de Enfermagem da UAENF/ CFP/UFCG no desenvolvimento de ações do projeto de extensão universitário intitulado: "Promoção à saúde biopsicossocial de crianças e adolescentes em isolamento social no contexto da COVID-19".

O referido projeto recebeu o pseudônimo promovesaúdecz, com o objetivo de facilitar a comunicação nas redes sociais e foi desenvolvido durante os meses de agosto a dezembro de 2020, por uma equipe de trabalho composta por docentes e discentes do curso de graduação em Enfermagem da UAENF/CFP/UFCG. O promovesaúdecz recebeu o apoio dos profissionais que integram a Escola de Futebol Estrelas do Futuro e de colaboradores externos. Dessa forma, foi possível alcançar, por meio de atividades remotas e presenciais, respeitando-se o distanciamento social, o público-alvo do projeto que consistiu em estudantes da referida escola, que se encontra localizada no município de Cajazeiras-PB. Vale salientar que a instituição atende a 140 sujeitos com idade entre 3 e 17 anos.

\section{Período e organização da produção dos dados}

Os dados que compõem o presente relato foram produzidos no período de agosto a dezembro de 2020, durante as vivências do projeto, sua organização e análise ocorreu no período de setembro de 2020 a janeiro de 2021. Verifica-se que, em dado momento, o processo de análise ocorreu concomitantemente à coleta de dados, por adotar um processo em que as categorias empíricas e as hipóteses explicativas se constituem a partir dos dados 
com o propósito de refletir e analisar resultados parciais, visando adequar melhor os procedimentos e coletas de dados para as ações subsequentes (SOARES et al., 2016).

Adotou-se como instrumento para sistematização dos dados o formulário de acompanhamento de projeto de extensão disponibilizado pelo PROBEX/PROPEX. Dessa forma, os dados foram organizados e analisados, mensalmente, utilizando-se os programas Microsoft Office Word e Microsoft Office Excel, ambos versão 2016.

\section{Delineamento das ações educativas}

As ações educativas foram estruturadas em tópicos relacionados aos objetivos do projeto de extensão, houve flexibilização para que outras temáticas relevantes que pudessem surgir ao longo da execução do projeto fossem exploradas, desde que não fujam aos objetivos.

Como a proposta do projeto contemplava uma abordagem biopsicossocial, suas ações foram inspiradas nas cinco dimensões que contemplam as competências socioemocionais (autoconhecimento; autogerenciamento; percepção social; relacionamento interpessoal e tomada de decisão responsável), a partir do modelo proposto pelo Collaborative for Academic, Social and Emotional Learning (CASEL, 2015).

Para planejamento das atividades, utilizaram-se materiais pré-selecionados na literatura, tanto relacionados à COVID-19 quanto a outros assuntos que têm relevância na saúde biopsicossocial das crianças e adolescentes. Além disso, todas as atividades propostas foram discutidas através das reuniões mensais que ocorreram pela plataforma google meet. Esses momentos foram conduzidos pela coordenadora do projeto, que assumiu o papel de facilitadora ao conduzir o grupo de forma harmoniosa e participativa, esclarecendo e aprofundando temas específicos.

Após a etapa de planejamento mensal das atividades, procedeu-se com a execução semanal delas. Para estimular a autonomia e o desenvolvimento do senso crítico e criativo dos estudantes, eles foram distribuídos em grupos de trabalho (GTs), que também contavam com a participação de uma professora orientadora e um colaborador externo. Cada grupo de trabalho ficava responsável por conduzir as atividades online durante uma semana do mês. No mês seguinte, os componentes dos GTs eram realocados para que todos tivessem a oportunidade de exercitar o trabalho em equipe e compartilhar saberes.

Dessa forma, seguiu-se com a execução das atividades em duas etapas concomitantes: atividades online e atividades presenciais. Para a etapa online, a equipe do projeto utilizou como recursos para interação com o público-alvo vídeos educativos sobre diversos assuntos, cards, enquetes, games e lives nas redes sociais. Utilizaram-se as novas Tecnologias da Informação e Comunicação (TICs), com ênfase nos aplicativos de mídia social, como Instagram, Facebook e WhatsApp. Ressalta-se que o desenvolvimento das TICs vem impactando substancialmente na produção e distribuição de conhecimentos, na cultura e no ensino (ROCHA, 2015). 
Nessa perspectiva, a escolha em realizar ações online e presenciais apresentou como principal referencial as ideias de Moran (2007, p. 12), ao afirmar que "[...] se ensinar dependesse só de tecnologias, já teríamos achado as melhores soluções há muito tempo. Elas são importantes, mas não resolvem as questões de fundo".

Já para a etapa presencial, foi utilizada a explanação expositiva-dialogada com o auxílio de objetos demonstrativos, além da dramatização de situações hipotéticas relacionadas ao contexto pandêmico. Essas atividades tiveram como facilitadores: a coordenadora do projeto, um colaborador externo e dois estudantes extensionistas. Vale salientar que as atividades levaram ao público-alvo informações sobre promoção em saúde, além de entretenimento para as crianças e adolescentes, que ainda não estavam adaptadas ao distanciamento social em decorrência da pandemia.

\section{Resultados}

Por considerar a relevância das recomendações da Organização Mundial de Saúde para a COVID-19, o projeto contemplou diversas propostas de atividades à distância, sendo assim, as ações foram, em sua maioria, realizadas por meio das redes sociais. Porém, com a colaboração dos funcionários da Escola de Futebol Estrelas do Futuro e de alguns componentes da equipe do projeto, ainda foi possível realizar três ações presenciais na referida escola.

Com relação às temáticas exploradas por meio dos canais de comunicação do projeto, no que se refere à saúde biopsicossocial, destacaram-se: Principais impactos da COVID-19 na vida das crianças; cuidados com a saúde mental dos adolescentes durante a pandemia; nutrição de crianças e adolescentes em tempos de pandemia; direitos da criança e do adolescente no contexto da COVID-19; prevenção de acidentes domésticos para crianças; setembro amarelo: aspectos de cuidado à saúde mental na infância e adolescência; importância do uso da máscara em esportes ao ar livre; diabetes na infância e adolescência; importância da hidratação para manter o corpo saudável; novembro azul: cuidados com a higiene pessoal e fimose em meninos; a pandemia não acabou, continue com as medidas preventivas; teste de conhecimentos sobre a COVID-19; ideias de brincadeiras para os pais realizarem com as crianças nas férias e durante o isolamento social.

As temáticas "Principais impactos da COVID-19 na vida das crianças" e "Cuidados com a saúde mental dos adolescentes durante a pandemia" foram abordadas da seguinte forma: inicialmente, os extensionistas escolheram textos para realizar a leitura e, em seguida, foram produzidos cards que contemplavam os referidos assuntos. A produção desses materiais foi de suma importância para o enfrentamento da pandemia, visto que, por se tratar de um momento em que houve várias mudanças, as crianças e os adolescentes poderiam ter sua saúde mental afetada. Isso porque foram privadas de realizar muitas atividades de rotina e isso pode repercutir negativamente na forma como elas percebem a si mesmas, ao outro e à 
sociedade em que vivem. Por fim, o material foi disponibilizado para o público-alvo a partir do Instagram e Facebook do projeto e pelo grupo do WhatsApp.

Já as temáticas "Nutrição de crianças e adolescentes em tempos de pandemia", "Direitos da criança e do adolescente no contexto da COVID-19", "Prevenção de acidentes domésticos para crianças", "Setembro amarelo: aspectos de cuidado à saúde mental na infância e adolescência", foram abordadas por meio de lives que ocorreram no Instagram do projeto. Vale destacar que, na prévia das lives, foram disponibilizadas ferramentas do tipo caixa de diálogo nas redes sociais: Facebook e Instagram, de forma que as crianças, adolescentes e pais pudessem expor suas dúvidas acerca das temáticas supracitadas que seriam debatidas nas lives.

Nessa perspectiva, a equipe do projeto se encarregou de repassar os questionamentos do público-alvo para os palestrantes e eles foram respondidos ao decorrer das lives. Estas transmissões ao vivo foram bastante promissoras, pois trataram de temas relevantes, que ainda são alvo de muitas dúvidas, não apenas para as crianças, adolescentes e pais, mas até mesmo para os extensionistas. Com isso, foi possível sanar as dúvidas que surgiram, além de proporcionar novos conhecimentos para todos.

Também foram produzidos materiais educativos, em forma de cards, relacionados a "Importância do uso da máscara em esportes ao ar livre" e "Diabetes na infância e adolescência" (Figura 1). Algumas pessoas expressaram dúvidas sobre o uso da máscara em esportes ao ar livre e, com a produção desse material, foi possível sanar essas dúvidas. Foi explicado que a máscara deve, sim, ser utilizada, visto que, se o indivíduo estiver em um local público, há riscos de se contaminar com o vírus, bem como de contaminar outras pessoas. Concomitantemente, foi orientado que, além do uso de máscara, a higienização das mãos, o isolamento/ distanciamento social são as principais formas de prevenção ao vírus (OMS, 2020).

Essas informações foram de grande relevância para as crianças da Escola de Futebol, já que estavam sempre juntas, praticando o esporte, e podiam não se atentar à importância do uso da máscara e demais medidas de prevenção durante esse tempo em que estivessem reunidos. O card sobre o diabetes também se fez muito importante, pois constava a diferença entre diabetes do tipo 1 e diabetes do tipo 2, o que fazer quando confirmado o diagnóstico e os sintomas para os quais os pais precisam estar atentos.

Os materiais produzidos foram disponibilizados nas redes sociais em forma de cards, para o público-alvo, bem como para os pais, para que assim pudessem ter os cuidados necessários com seus filhos, tanto em relação à pandemia quanto ao diabetes, que é algo que afeta bastante esse público e que ainda é alvo de muitas dúvidas para os pais, pois muitos acabam sem saber como lidar com essa situação. 
Figura 1- Card informativo sobre diabetes na infância e adolescência.

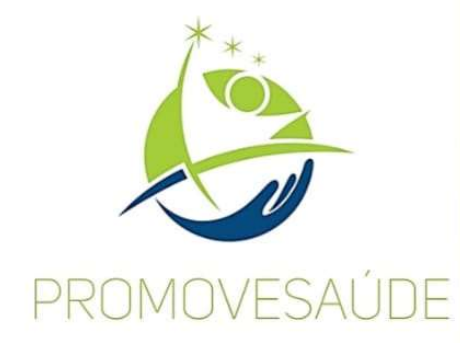

Diabetes na Infância e Adolescência

Promoção à saúde biopsicossocial de crianças e adolescentes em isolamento social no contexto da COVID-19.

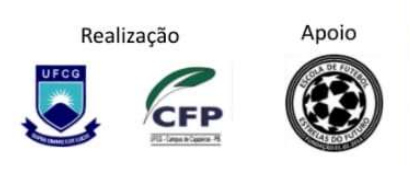

Fonte: Arquivo do projeto.

\section{Diabetes na Infância e Adolescência}

O diabetes do tipo 1 é o mais comum em crianças. Acontece devido à destruição das células do pâncreas, que são as responsáveis pela produção de insulina, hormônio responsável pelo controle da glicose no sangue. Esse tipo de diabetes infantil não tem cura, apenas controle, que é feito principalmente com uso de insulina, conforme orientação do pediatra. Apesar do diabetes do tipo 1 ser mais comum, crianças que possuem hábitos de vida pouco saudáveis podem desenvolver o diabetes do tipo 2, que pode ser revertido em sua fase inicial por meio da adoção de hábitos saudáveis, alimentação balanceada e a prática de atividades físicas.

Fonte: Fiocruz
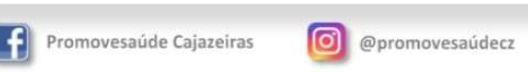

Os temas "Importância da hidratação para manter o corpo saudável" e "Novembro azul: cuidados com a higiene pessoal e fimose em meninos" foram abordados por meio de vídeos educativos, sendo que o primeiro foi produzido pelos extensionistas, com o auxílio dos professores, e o segundo foi produzido por uma médica pediatra, e ambos trataram de assuntos muito importantes para o público-alvo.

O vídeo sobre a hidratação contou com um conteúdo rico em informações, mostrando o quão importante é manter-se hidratado, o quanto de água deve ser ingerida por dia e diversas outras dicas importantíssimas para manter uma boa saúde. Já o vídeo sobre o novembro azul contou com uma explanação bem detalhada sobre a higiene pessoal e fimose, possibilitando que as crianças e adolescentes soubessem como fazer essa higienização de forma correta, e, além disso, pudessem tirar dúvidas a respeito da fimose. Esses vídeos foram publicados nas redes sociais e disponibilizados no grupo do WhatsApp, para que as crianças, adolescentes e seus pais pudessem ter acesso.

O tema "a pandemia não acabou, continue com as medidas preventivas" foi abordado por meio de um vídeo educativo que contemplou várias informações acerca do novo 
coronavírus, reforçando os cuidados que devem ser tomados. Esse vídeo foi publicado no Facebook, Instagram e no grupo do WhatsApp, para que o público-alvo pudesse ter acesso e, assim, dirimir as dúvidas a respeito do assunto.

Ainda, foi produzido um teste de conhecimentos sobre a COVID-19, que foi desenvolvido com o intuito de verificar o que as crianças já sabiam a respeito da COVID-19. O material contemplou perguntas de nível de fácil compreensão, já que o público para o qual ele foi destinado são crianças. O teste foi disponibilizado em forma de card e enquete, com imagens ilustrativas em cada uma das alternativas; ele foi postado no Facebook, Instagram e no grupo do WhatsApp, para que o público-alvo pudesse ter acesso.

Entre as perguntas do teste, estavam: "a COVID-19 é uma doença causada por", e como alternativas havia "vírus ou bactéria"; "quais as formas de transmissão do novo coronavírus?", e como alternativas "espirro, tosse, gotas de sangue"; "qual o órgão mais comprometido pelo novo coronavírus?", e como alternativas "pulmão ou estômago"; "qual a maneira correta de sair na rua?", e como alternativas "com máscara ou sem máscara"; "ao chegar em casa, qual a primeira coisa que se deve fazer?", e como alternativas "lavar as mãos ou ir se alimentar"; "a pandemia da COVID-19 está afetando", e como alternativas "o mundo todo ou apenas o Brasil"; "qual tipo de álcool gel é eficaz na proteção contra o coronavírus?", e como alternativas "álcool gel 70\% ou álcool gel 46\%".

Para a finalização das atividades a distância, foram produzidos dois vídeos contemplando o tema: "Ideias de brincadeiras para os pais realizarem com as crianças nas férias e durante o isolamento social". Esses vídeos foram também elaborados pelos extensionistas, a partir de ideias pré-selecionadas e apresentadas à professora coordenadora do projeto; após serem produzidos, eles foram publicados nas redes sociais do projeto.

Os extensionistas consideraram o tema da atividade acima descrita pertinente, visto que, devido à pandemia, as crianças e os adolescentes não podem sair para se divertir, e por isso foram propostas atividades simples que pudessem ser feitas dentro de casa, para evitar qualquer tipo de aglomeração e risco à saúde dos envolvidos. As brincadeiras propostas nos vídeos foram: boliche com garrafas, raquete para balões de festa, jogo da memória, teatro de fantoche, pega varetas, bolinha na colher e encaixe de formas.

No que diz respeito às ações presenciais, vale destacar que foi proporcionada, aos discentes do curso de Enfermagem, uma aproximação com a realidade das crianças e adolescentes, permitindo-lhes conhecer melhor esse público-alvo, bem como lhes transmitir maiores informações sobre saúde, principalmente acerca da COVID-19. Destaca-se que algumas crianças e adolescentes não tinham acesso às informações de forma correta, o que lhes acarretava dúvidas a respeito de tudo o que estava acontecendo.

Assim, as ações presenciais proporcionaram uma experiência satisfatória. O contato com as crianças e adolescentes facilitou, sem dúvida, a troca de informações e permitiu aos discentes a observação dos conhecimentos preexistentes do público-alvo sobre a pandemia. 
Como já mencionado, foram realizadas três ações presenciais, cada uma com uma temática diferente, porém todas relacionadas à COVID-19.

$\mathrm{Na}$ primeira ação presencial realizada, foi trabalhada a temática da higienização correta das mãos. Na oportunidade, a equipe apresentou "a dinâmica da caixa preta", que consistia em uma caixa artesanal de papelão escurecida, com uma luz negra interna, entradas para as duas mãos e um visor superior para a visualização, onde, após "contaminar" as mãos com uma solução fluorescente, os alunos podiam ver onde se concentrava a sujeira que normalmente está presente nas mãos (Figura 2). Após lavar as mãos de maneira correta, o participante poderia inserir novamente as mãos no receptáculo e constatar se conseguiu realizar a higienização das mãos de forma satisfatória.

Figura 2 - Demonstração da "dinâmica da caixa preta" para observar a sujeira presente nas mãos.

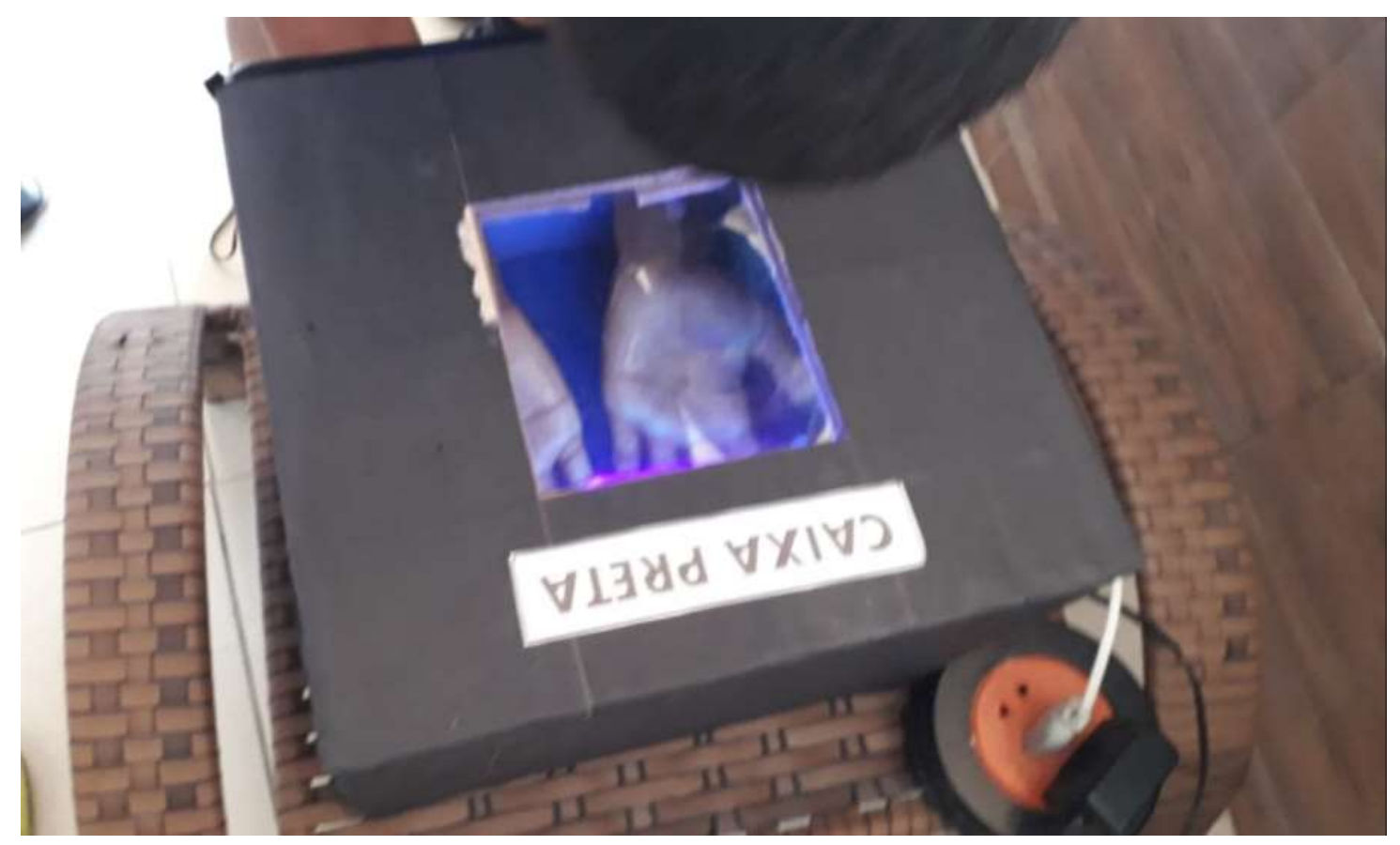

Fonte: Fotografia dos autores.

A dinâmica da caixa preta foi precedida por uma breve explicação do procedimento e informações a respeito do tema. Contou, ainda, com uma recompensa para aquele que melhor lavasse as mãos e, além disso, foram feitos comentários, por parte dos alunos, da Escola de Futebol, avaliando a experiência na atividade, a qual foi muito bem recebida e considerada bem-sucedida pelos presentes. Por fim, foi entregue as crianças e adolescentes um card sobre higienização das mãos, produzido pelos extensionistas, contemplando de forma ilustrativa cada um dos passos para a correta higienização das mãos (Figura 3). 
Figura 3 - Card sobre higienização das mãos.

\section{HIGIENIZAÇÃO DAS MÃOS}

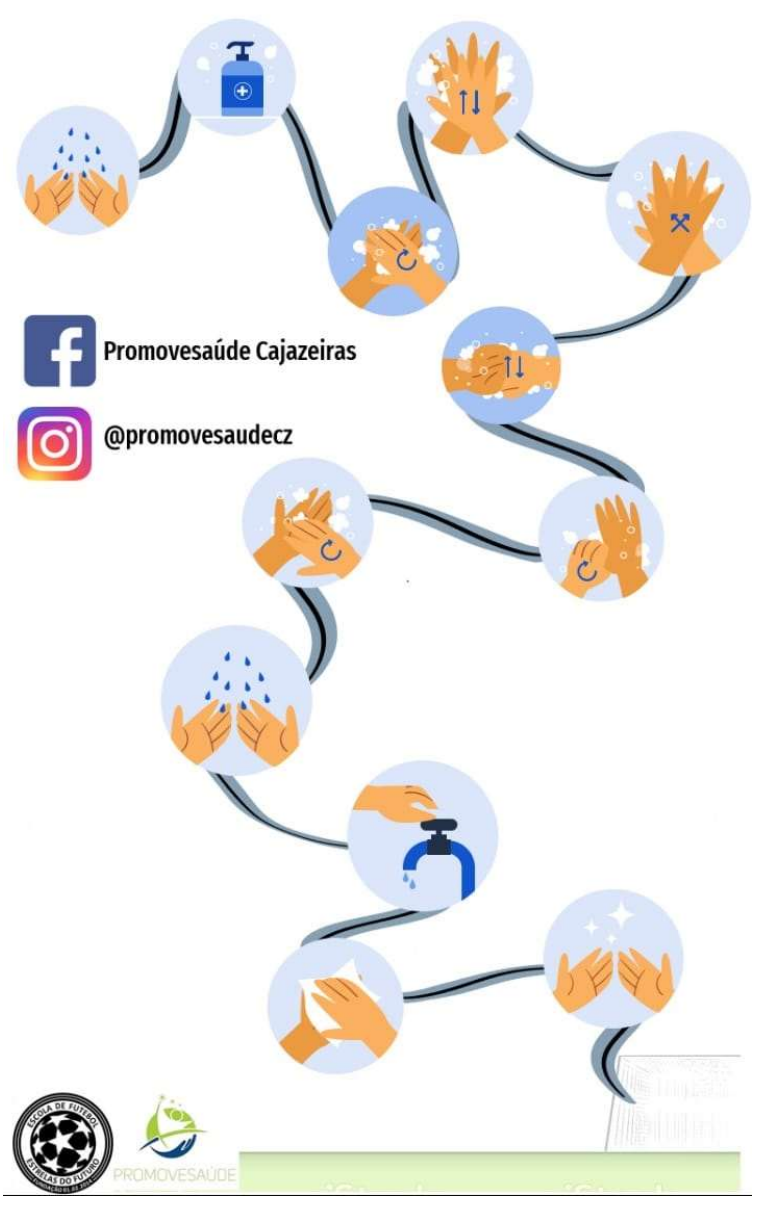

Fonte: Arquivo do projeto.

O uso adequado da máscara foi o tema abordado na segunda ação presencial com os alunos da Escola de Futebol, os quais já estavam familiarizados com a equipe, e se mostraram ainda mais receptivos nesta ação. A abordagem utilizada nessa ação foi bastante simples, sendo realizada uma explanação breve diante dos alunos no intervalo das atividades que estavam desenvolvendo. Foram utilizadas máscaras para demonstrar as formas seguras de manuseá-las e discursado sobre as principais recomendações para o seu uso seguro (Figura 4). Além disso, os alunos mostraram-se mais atenciosos e interessados, inclusive esclareceram algumas dúvidas e comentaram sobre suas experiências em casa. 
Figura 4 - Extensionista demostrando às crianças e aos adolescentes a forma correta de se utilizar a máscara.

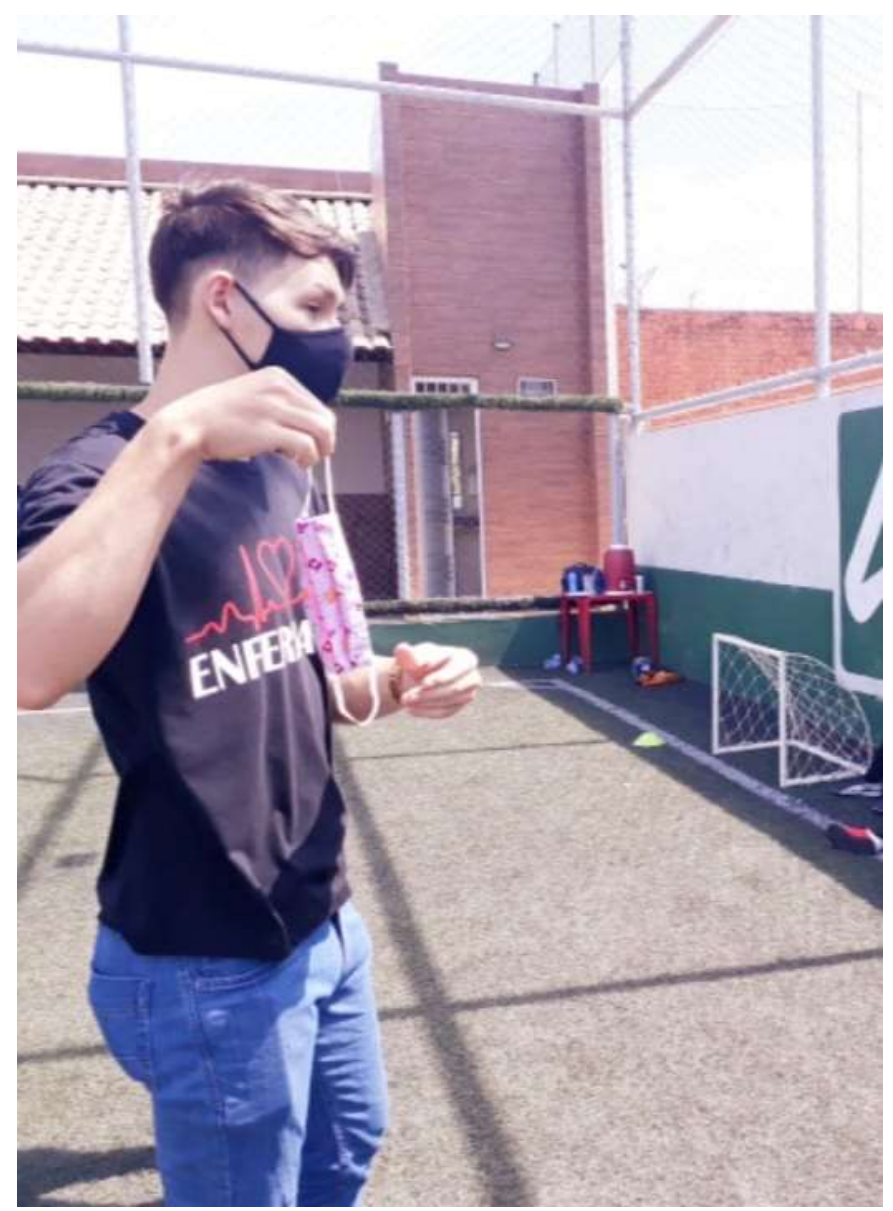

Fonte: Fotografia dos autores.

Na terceira e última ação presencial da vigência do projeto Promovesaúdecz, foi abordado o tema: "cuidados que devem ser seguidos durante as confraternizações de fim de ano". A equipe realizou uma distribuição de cards informativos contendo dicas e recomendações para a organização de reuniões familiares tradicionais de fim ano, preservando o distanciamento e as medidas de higiene que devem ser seguidas para evitar contaminações pelo vírus (Figura 5). Assim como nos demais encontros, os alunos demonstraram-se atenciosos e interessados com a presença da equipe do projeto. Ao final, os extensionistas agradeceram à colaboração de todos durante os trabalhos que foram executados no ano, e distribuíram chocolates, a fim de se confraternizarem e celebrarem as conquistas e amizades alcançadas. 
Figura 5 - Card informativo entregue às crianças e aos adolescentes sobre cuidados nas confraternizações de fim de ano.

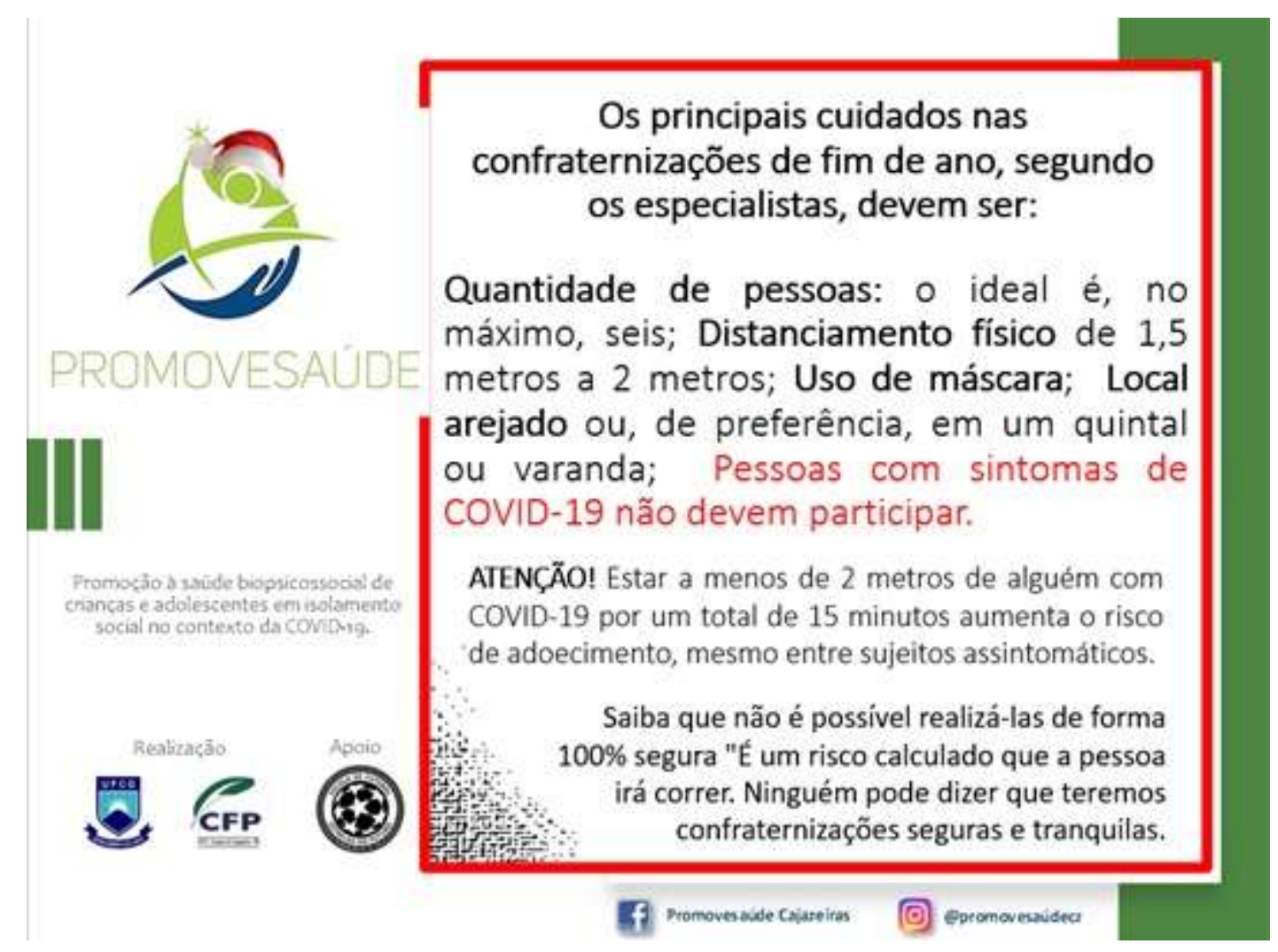

Fonte: Arquivo do projeto.

Vale destacar que, de forma presencial, o público-alvo recebeu as informações de maneira bastante eficaz, isso graças aos métodos usados para melhor fixação dos temas propostos pelos integrantes do projeto. Dessa forma, fica evidente a importância que as ações presenciais tiveram para melhor alcance dos objetivos do projeto.

Sendo assim, as atividades desenvolvidas neste projeto, tanto presenciais quanto pelas redes sociais, fizeram com que os acadêmicos de enfermagem se envolvessem de forma efetiva com as crianças e adolescentes da escola, e conhecessem um pouco mais sobre eles, para assim transmitirem informações com respaldo científico, que possam contribuir para o enfrentamento da pandemia.

Ressalta-se, ainda, que as expectativas do projeto foram atendidas, pois durante a execução das ações, os extensionistas conseguiram alcançar o público-alvo com as estratégias que haviam planejado previamente. Além disso, as crianças e adolescentes se mostraram bastante 
interessados pelas atividades, o que contribuiu para a motivação da equipe e favoreceu o vínculo entre comunidade e extensionistas.

Durante a experiência no período de realização do projeto, observou-se que, por mais que a pandemia e o vírus estivessem sendo constantemente debatidos, dúvidas de melhores maneiras para seu enfrentamento ainda eram recorrentes, a exemplo de: as formas corretas da higienização das mãos; como recrear e fornecer aprendizado em casa para as crianças; as melhores formas de explicar-lhes como age o vírus e sua proliferação.

Dessa forma, a equipe executora do projeto buscou disseminar conhecimento com respaldo científico, sanar dúvidas e auxiliar, principalmente, os pais acerca de suas principais preocupações, que foram atendidos em grande demanda na etapa online do projeto. Quanto à etapa presencial, que foi realizada na escola de futebol, contemplando as crianças, adolescentes e seus instrutores, verificou-se que a participação e interesse deles era evidente, mantendose atentos às informações repassadas, interagindo por meio de perguntas e comentários, demostrando, assim, a relevância das atividades do projeto.

A experiência proporcionada pelo projeto é, de fato, enriquecedora para ambas as partes que estiveram nele envolvidas. Dessa forma, em relação ao público-alvo do projeto (crianças, adolescentes e responsáveis), acredita-se que as informações foram de grande valia para o autocuidado e proteção dos indivíduos, tendo em vista tal necessidade para o enfrentamento do período em que foi executado o projeto. Já em relação aos extensionistas e profissionais, a experiência contribuiu para a formação e o aperfeiçoamento do "ser profissional" de forma ímpar, pois, para além do conhecimento que o contato com a comunidade proporciona, foi possível exercitar o desenvolvimento e aprendizado de uma nova forma de abordagem, em vista do atual cenário de pandemia, aproximando os estudantes e profissionais das TICs como forma de contato e interação com a sociedade.

Entre as descobertas, facilidades, dificuldades e recomendações, destaca-se que a participação no projeto proporcionou um leque de descobertas a cada integrante da equipe. Uma das principais descobertas foi sobre a importância da extensão universitária na sociedade e como essa ação influencia de maneira positiva nas ações cotidianas do público-alvo do projeto, a partir da educação em saúde. Descobriu-se, também, que se aprende muito mais do que se ensina e o quanto é fértil e mútua a troca de saberes. Ao longo do percurso, foi possível contar com facilidades que tornaram os dias mais flexíveis e produtivos. Nesse contexto, foram consideradas facilidades à receptividade do público-alvo, o interesse pelas informações e a credibilidade que foi estabelecida na relação de convívio, ainda que de maneira virtual.

Como todo e qualquer desafio, as dificuldades também estiveram presentes, a exemplo da comunicação remota, instabilidade de conexão e o esforço necessário para desconstruir as fakes news em saúde e, em especial, relacionadas à COVID-19. As recomendações feitas através das mídias sociais alcançaram não somente a escolinha estrelas do futuro, mas centenas de pessoas que estavam navegando nas redes sociais e se deparavam com os pôsteres contendo informações seguras e indispensáveis sobre o contexto pandêmico. 
A vivência oportunizada pelo projeto demonstra dissociação com a teoria descrita pela literatura. Natividade et al. (2020) apontaram que as medidas protetivas são mais bem aceitas por indivíduos adultos do que por crianças e adolescentes, por restringirem o lazer e o contato social; entretanto, os alunos da escolinha participantes do projeto, em suas atividades presenciais, gozavam dessas experiências por praticarem uma atividade recreativa e em grupo.

Já Linhares et al. (2020) apontaram as poucas opções de estímulo e desenvolvimento dos que estão restritos do convívio externo, o que, novamente, não é o caso dos participantes, tendo em vista as atividades semanais presencialmente e em conjunto com outros indivíduos da mesma faixa-etária. Por fim, Florêncio Júnior et al. (2020) desenvolveram sobre as consequências físicas do isolamento social, principalmente para crianças e adolescentes, que estariam mais sujeitos/as ao sedentarismo de atividades estáticas. Isso, mais uma vez, se distancia da realidade dessas crianças e adolescentes, por serem atletas em formação.

Para a avaliação do projeto, foi disponibilizado um questionário avaliativo para os alunos da escola de futebol, os pais ou responsáveis dos alunos, funcionários da escola, orientadora, extensionistas e colaboradores externos, contemplando perguntas relacionadas ao que foi realizado no projeto, tanto relacionado à COVID-19 quanto aos demais temas, e como isso contribuiu para a vida de cada um, sendo possível observar, através desse questionário, a real contribuição do projeto na vida dos envolvidos.

Todas as respostas do questionário ocorreram de forma positiva, demostrando-se a sua importância durante período tão difícil não só para a comunidade externa do projeto (crianças, adolescentes e pais) como também para a equipe executora (extensionistas, colaboradores, orientadoras e coordenadora), demostrando-se, assim, o quão essencial se fez o trabalho realizado no projeto.

\section{Conclusão}

Tendo em vista o cenário atual em que a população mundial está inserida, o projeto de extensão "Promoção à Saúde Biopsicossocial de Crianças e Adolescentes em Isolamento Social no Contexto da Covid-19" possibilitou o repasse de informações a respeito da COVID19 para crianças e adolescentes da Escola de Futebol Estrelas do Futuro, bem como para os pais e responsáveis, além de proporcionar a troca de experiência entre a equipe do projeto e o público-alvo.

Os objetivos do projeto foram alcançados, tanto no que se refere ao público-alvo e a partilha de informações quanto no desenvolvimento das habilidades dos extensionistas. Além disso, os temas abrangidos foram, de fato, pertinentes, pois, como já citado anteriormente, a cena que se passa no mundo exige que os indivíduos tenham informações de proteção pessoal, higiene e distanciamento, para que o número de infectados diminua. Em adição, o projeto parte da premissa de que é necessário educar os jovens para se criar uma população mais consciente e responsável. 
O projeto atuou também como um inibidor das informações falsas (fake news), uma vez que foi responsável por difundir informes científicos, combatendo a cultura das instruções falsas ou infundadas, que tanto prejudicaram o repasse das orientações corretas, sobretudo nesse momento de crise sanitária. As crianças, adolescentes, pais e profissionais da escola estrelas do futuro tiveram como alternativa, com o advento do projeto, o acesso - de maneira prática e segura - às novas atualizações sobre a COVID-19 e as maneiras de se proteger individualmente e coletivamente, em meio a um turbilhão de informações dispersadas nas redes sociais, sem nenhum critério ou fundamentação.

Vale destacar que as redes sociais foram um importante instrumento de promoção da saúde biopsicossocial, permitindo que as informações chegassem a muitas pessoas, além do público-alvo.

Houve também uma grande contribuição do projeto no processo de formação acadêmica dos discentes de Enfermagem, o qual proporcionou que os extensionistas repassassem informações sobre promoção em saúde para as crianças e adolescentes e demais pessoas que acompanharam o trabalho, já que esse é um dos principais papéis do profissional da Enfermagem.

Portanto, o projeto foi de grande valia para o momento, contribuindo para o enfrentamento da pandemia, e, além disso, contribuiu para o aprimoramento do processo formativo dos extensionistas.

\section{Referências}

ALMEIDA, Lúcia Helena Rios Barbosa et al. Ensinando e aprendendo com portadores de Esclerose Múltipla: relato de experiência. Rev Bras Enferm, Brasília, v. 60, n. 4, p. 460463, jul./ago., 2007. Disponível em: https://www.scielo.br/pdf/reben/v60n4/a20.pdf. Acesso em: 09 jan. 2021.

CASEL. Casel Guide: Effective Social and Emotional Learning Programs. 2015. Disponível em: http://secondaryguide.casel.org/. Acesso em: 08 jan. 2021.

FLORÊNCIO JÚNIOR, Públio Gomes; PAIANO, Rone; COSTA, André dos Santos. Isolamento social: consequências físicas e mentais da inatividade física em crianças e adolescentes. Rev Bras Ativ Fís Saúde, v. 25, p. 1-2, 2020. Disponível em: https://docs.bvsalud.org/biblioref/2020/10/1121597/14263-texto-do-artigo-55483-110-20200914.pdf. Acesso em: 09 jan. 2021. 
LINHARES, Maria Beatriz Martins; ENUMO, Sônia Regina Fiorim. Reflexões baseadas na Psicologia sobre efeitos da pandemia COVID-19 no desenvolvimento infantil. Estud. psicol. (Campinas), Campinas, v. 37, jun., 2020. Disponível em: https://www.scielo.br/scielo.php?script=sci_arttext\&pid=S0103-166X2020000100510. Acesso em: 09 jan. 2021.

MORAN, José Manuel; MASETTO, Marcos T.; BEHRENS, Marilda Aparecida. Novas tecnologias e mediações pedagógicas. 13. ed. São Paulo: Papirus, 2007.

NATIVIDADE, Marcio dos Santos et al. Distanciamento social e condições de vida na pandemia COVID-19 em Salvador-Bahia, Brasil. Ciênc. saúde coletiva, Rio de Janeiro, v. 25, n. 9, p. 3385-3392, ago., 2020. Disponível em: https://www.scielo.br/scielo.php?pid=S1413$81232020000903385 \&$ script=sci_abstract\&tlng=pt. Acesso em: 08 jan. 2021.

OMS. Organização Mundial da Saúde. Uso de máscara no contexto de COVID-19: orientação provisória. 2020. Disponível em: https://www.who.int/publications/i/item/advice-on-the-use-of-masks-in-the-communityduring-home-care-and-in-healthcare-settings-in-the-context-of-the-novel-coronavirus(2019-ncov)-outbreak. Acesso em: 18 mar. 2021.

OPAS. Organização Pan-Americana da Saúde. Considerações para quarentena de indivíduos no contexto de contenção da doença causada pelo novo coronavírus (COVID19). OPAS, 2020. Disponível em: https://iris.paho.org/bitstream/handle/10665.2/51956/OPASBRACOVID1920018_por.pdf?s equence $=1 \&$ is Allowed $=\mathrm{y}$. Acesso em: 03 fev. 2021

ROCHA, Juan Stuardo Yazlle. Uso de tecnologias da informação e comunicação na educação em saúde. Problematização e desenvolvimento. Medicina (Ribeirão Preto), v. 48, n. 3, p. 214-223, 2015. Disponível em:

https://www.revistas.usp.br/rmrp/article/view/104297/102943. Acesso em: 08 jan. 2021.

SENHORAS, Eloi Martins. Coronavírus e educação: Análise dos impactos assimétricos. Boletim de Conjuntura (BOCA), v. 2, n. 5, p. 128-136, 2020.

SOARES, Mirelle Inácio; CAMELO, Silvia Helena Henriques; RESCK, Zélia Marilda Rodrigues. A técnica de grupo focal na coleta de dados qualitativos: Relato de experiência. REME - Rev Min Enferm, v. 20, 2016. Disponível em: https://cdn.publisher.gn1.link/reme.org.br/pdf/e942.pdf. Acesso em: 18 mar. 2021 